\title{
THE WRATH OF ARTEMIS (AND MENIS!) IN AG. 122-159
}

\section{F. Saayman, University of the North}

In the parodos of the Agamemnon of Aeschylus an omen appears in which two eagles kill and eat a female hare as well as her unborn young. This is seen by the seer Calchas to symbolize that Agamemnon's fleet wil destroy Troy and all its inhabitants. But the goddess Artemis is angry at something about this portent, and there is fear that she will demand a sacrifice of atonement. Opinions have differed widely as to the cause of this anger. Some scholars (e.g. Page and Lawrence) limit Artemis to the physical portent, while others (e.g. Peradotto, Lebeck, Whallon) involve her in the imagistic side of the portent. At the end of Calchas' speech there is an apparently loosely connected and unmotivated reference to a Menis as also being the cause of such a sacrifice. If the roles of Artemis and this Menis are not clearly distinguished, the whole problem of the extent of Artemis' reason for the sacrifice cannot be resolved. Lack of distinction between these two personae is evident in Whallon's absurd confusion of the roles of Artemis and Menis: "The visitations of her (i.e. Artemis') wrath produced an endless continuance of teknophagy. For like the Erinyes she was a deity whose punitive actions became predacious and necessitated further punishment" (1961:87). Since Erinyes and the Menis are of the same type, Whallon implies that there is little difference between Artemis and Menis. The.problem about the extent of Artemis' anger can be solved if it can be proved that Menis is textually motivated by the imagery, which will make it unnecessary to involve Artemis in the imagery. Lawrence showed how the imagery has been applied to Artemis without any reflection on the validity of the method, but he actually did not prove that it is wrong to make such a link. In his opinion Artemis is angered by the omen itself and not by its interpretation through the words of the seer Calchas.

In this article it will be argued that the anger of Artemis should not be applied to the symbolism in the text, but should be restricted to the physical portent for the following reasons:

1. Allusions to fundamental issues in the trilogy, such as created by the imagery, fit in better with Menis than with Artemis.

2. As regards sense, there is a transition from Artemis to Menis, which is formally marked by a ringcompositional antithesis between their names. In both instances the name is accompanied by the conjunction ráa to highlight the antithesis.

\section{The imagery}

In order to describe the semantic structures immediately after the text is given, a selection of the imagery in lines 122-159 is given here beforehand. Because an extensive listing of all the images and their themes will take up too much space, images have been selected to represent different vital aspects of the trilogy.

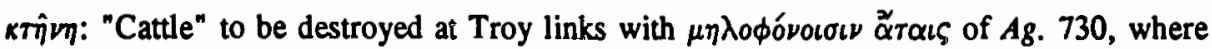
the lion cub grows up and shows its true character by killing the sheep of his owner. The same theme is touched on again when Clytaemnestra says that Agamemnon had enough 
sheep of his own, not to need to sacrifice his own daughter (Ag. 1416). Together with $\lambda \in$ fortwע (Ag. 141) of the section under discussion, this imagery serves the theme of personal responsibility. In the lion simile the image of the lion serves to suggest that crimes are caused by inherited natural character traits. Consequently the lion images in the parodos serve to suggest in a proleptic way that personal motivation plays a role in crime.

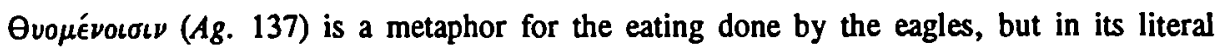
sense it alludes to the sacrifice of Iphigeneia. In the text it forms a compositional ring with $\delta \in \hat{i} \pi \nu 0 \nu$ (Ag. 138), "meal", which also in the first instance refers to the eagles' eating, but

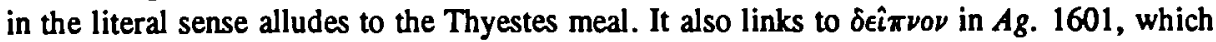
refers to the same. There Aegisthus relates how Atreus, the father of Agamemnon, killed some of Thyestes' children and served them to him at a banquet. When Thyestes discovered what had happened, he kicked over the table and pronounced a curse that the whole line of Atreus would be wiped out. The allusion to the Thyestes meal here, therefore, brings in that curse as a cause of the impending sacrifice of Iphigeneia.

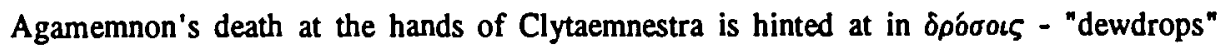

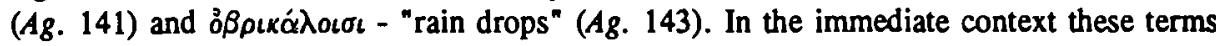
refer, by way of metaphor, to little animals loved by Artemis; but in their literal sense they culminate in Clytaemnestra's description of the murdered Agamemnon's spewing of blood

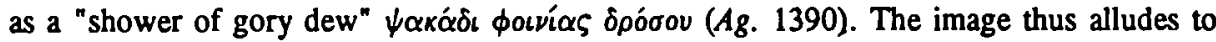
Agamemnon's death.

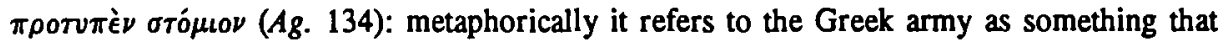
tames the Trojans, but literally it means "something put over the mouth before the time". In this sense it alludes to the sacrifice of Iphigeneia. The sacrifice scene is structured according to contrasts between sounds and the silencing of Iphigeneia lest she utter some ill-omened sound that would have evil consequences for Agamemnon. This is an Archaic conception, and is in contrast with Agamemnon's personal responsibility. But the image of a muzzle is also part of "restraining" imagery like "yoke" and "net, pointing to Agamemnon's death. Clytaemnestra murders Agamemnon by throwing a net over him while he is in the bath (Ag. 1382) and then stabs him to death.

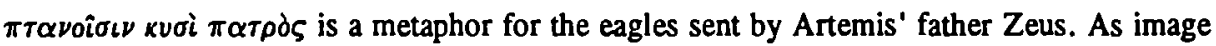
the "dog" splits into two themes, namely (1) justified, openly executed, revenge by hounds and (2) secretive treachery, in the name of revenge, by dogs in the house. In the case of Menelaus, the hound image is used in the execution of justified revenge (in Ag. 694

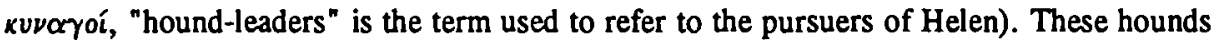
operate in collaboration with Menis who sent Helen to Troy to cause trouble (Ag. 699701). It also applies to the Erinyes. After Agamemnon's murder Orestes pledges to avenge

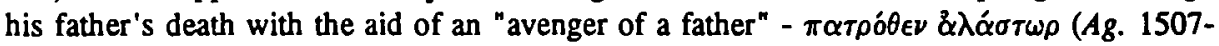
1509). In Cho. 924-925 he has to kill his mother in obedience to the "hounds of his father", which are Agamemnon's Erinyes. The dog as watchdog is applied to Clytaemnestra as a false watchdog ( $\mathrm{Ag}$. 607-608), who calls herself an incarnation of the Erinyes after the murder (Ag. 1476-1477 and 1500-1503). The dog image therefore is used either of humans collaborating with predeterministic forces of vengeance, or as metaphor for the Erinyes.

There can be no doubt that the imagery refers to crimes in the Pelopidae family, starting with the Thyestes meal and pointing into the future until the death of Clytaemnestra. Some of the imagery alludes to personal responsibility while others allude to a family curse and to the Erinyes. This distinction between external and personal motivation in the imagery is of vital importance because it forms an important part of the intrigue of the whole trilogy, namely what the causes of crime are. This distinction should, consequently, be taken into 
account when attempting to link Artemis or Menis to the imagery. If Artemis is involved in the imagery, we would expect her to be concerned with the imagery alluding to character and personal motivation, because she is not a force of vengeance like the Erinyes or Menis. This is the approach followed by Peradotto. He links Artemis' attitude to all hunting symbolism regarding the destruction of Troy in the Agamemnon, and then concludes: "... as patroness of innocent youth and fertility ... Artemis recoils from the indiscriminate predation which she knows a war under the Atreidae will be" (1969:246). This portended destruction is indicative of Agamemnon's character, just as the reference to the Thyestes meal points to Atreus' character. "It is this iं $\theta 0 \varsigma$ that Artemis chiefly hates" (Peradotto 1969:256). Peradotto's conclusion originates from a popular stance, namely that the text is too archaic (i.e. gods determine human fortunes in such a way that humans can work no safeguard against evil befalling them) if Artemis demands a sacrifice from the Atreidae simply because they are symbolized by the eagles in the portent. Page accepts that we do have such an archaic situation here: "The sacrifice of Iphigeneia ... is demanded by Artemis not because he (i.e. Agamemnon) has done or left undone anything, but because two eagles ... have devoured a pregnant hare" (1957:XXV). If we agree with Page that Artemis acts in an archaic way, then there would be a contrast between Artemis and the imagery alluding to character. Such a contrast would enhance the literary quality of the play instead of making it poorer, as Peradotto's interpretation does. If Menis is involved, as this author proposes, then obviously she cannot be involved in the imagery of character. Lebeck fails to draw these distinctions and links Artemis both to personal responsibility and predeterminism! On the one hand she says "Artemis requires payment for a transgression of which the omen is a symbol", while on the other hand she also equates Artemis to an Erinyes (Lebeck 1971:22). Likewise Whallon: "... the eagles and the hare create a timeless emblem of the recurring crime for which Artemis has a long-enduring -wrath" (1961:82). If one attempts to simplify the issues in the drama then there is the danger that it becomes a simple drama. It would be tempting to try and prove that Artemis is linked to the imagery which indicates character and that, in contrast, Menis is linked to the imagery indicating predeterminism. However, if one agrees with Page, then Artemis simply resides in the same general archaic predeterministic domain as Menis. This does not create a problem, not even to Agamemnon, because when he decides to sacrifice his child, he operates within the sphere of Homeric values. His decision is based on Homeric $\tau \mu \mu \dot{\eta}$, because the deciding factor for him is: "How can I become a deserter of the fleet and fail my allies?" (Ag. 212-213). His decision is based on the maintaining of his honour. He does not lash out at unfair demands or anything of the sort, unlike many critics. The whole setting of the ethics in the scenes of the omen and the sacrifice, especially on the narrative level, is that of Homeric and archaic ethical values. As the drama progresses, the imagery develops a contrast between predeterminism and personal motivation due to character. Because the interpretation of the omen starts out with Artemis, it was simply assumed that she is relevant in the imagery as well. However, no attention has been paid to stylistic devices and the possibility that Menis is linked to the imagery in a retrospective way. Artemis is also not a deity concerned with the upholding of justice and the perpetuating of "a family curse". On the other hand, Zeus, Menis and the Erinyes are throughout the trilogy such agents of this kind of justice. In Cho. 400-404 the Erinyes state that for blood

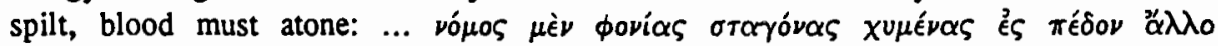

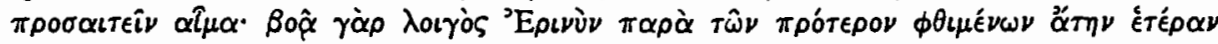

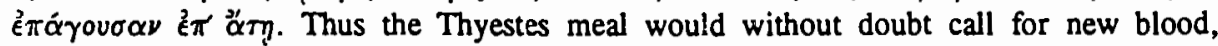
which explains the presence of the Menis.

A fundamental problem that has constantly been ignored, is whether the imagery was perceptible to Artemis or not. Most scholars treat only the imagery of the visible omen of the eagles eating the hare (e.g. Peradotto, Lebeck), linking Artemis to the physical omen which she could see. But they ignore the fact that we have here the words of Calchas, not 
describing what Artemis saw, but describing her attitude. In lines 140-144 her positive attitude is described, where she is kind to, and delighted with, "dew-drops" and "raindrops". These images are not visible in the omen, but originate from Calchas" description of the general nature of Artemis. This author consequently proposes that the imagery does not operate on the narrative level of characters and events, but on a higher level where the text communicates only with the audience. For example, on the narrative level the characters speak to each other and react in response to this textual level. On the other hand, the chorus as an ironic character constantly says more than they intended - only to the audience.

A limited discourse analysis helps to shed more light on the respective roles of Artemis and Menis.

\section{Discourse analysis of $\mathrm{Ag} \cdot \mathbf{1 2 2}-159$}

A discourse analysis reveals inter alia:

1. General ringcompositional features that support a transition from Artemis to Menis.

2. Artemis and Menis as alternative causes of possible disaster.

3. The initial negative attitude of Artemis is implicitly retracted to make way for the Menis.

4. The section dealing with Artemis is structured very intricately, thereby creating allusions to Menis.

The portent itself consists of two eagles devouring a hare full of unborn young. This is interpreted by Calchas that the Greeks would destroy Troy and its inhabitants. Immediately upon this, follows the fear that "some wrath from the gods" might hinder the expedition. This forms a heading for the main body of the text, which deals first with Artemis and then with Menis. After each strophe is a refrain "Say 'woe, woe', but may the good prevail". This is not included in the analysis.

In the following analysis the text is divided into groups of words serving a common theme and then the groups are linked to each other on the basis of semantic similarity or opposition. 


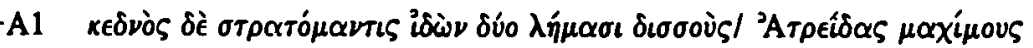

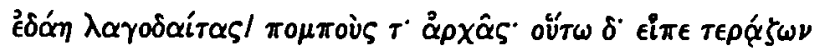

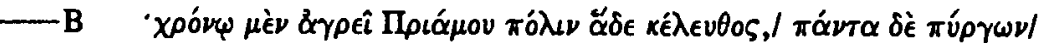

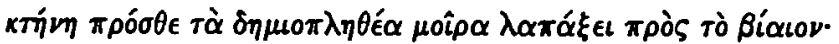

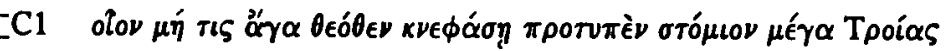
$\sigma \tau \rho \alpha \tau \omega \theta \dot{\epsilon} \boldsymbol{\nu} \cdot$

D1...E

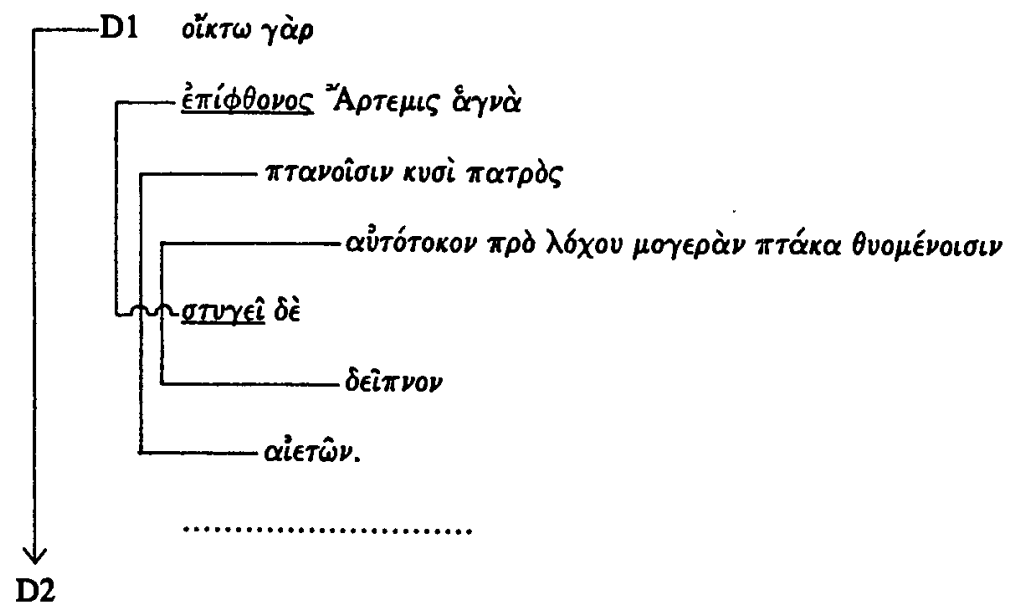


D1

؟ D2 тó

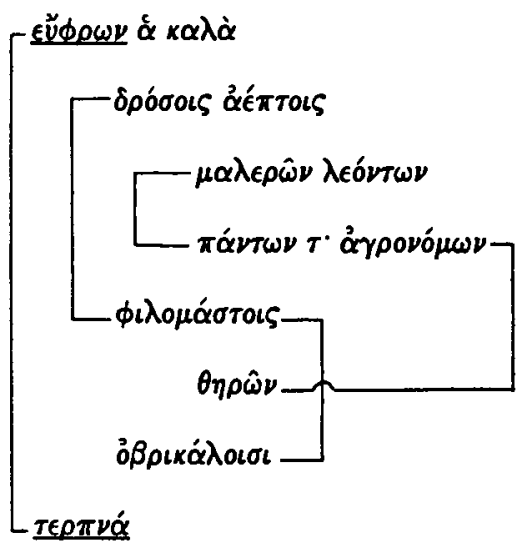

C1

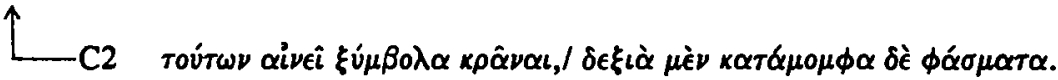

C1...C2

$\uparrow$

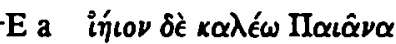

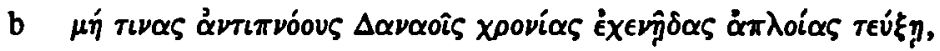

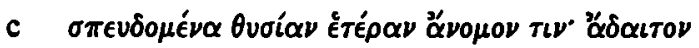

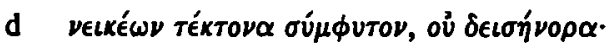

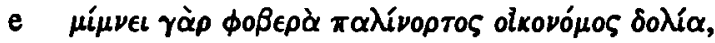

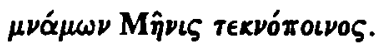

A1

$\uparrow$

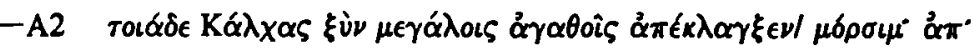

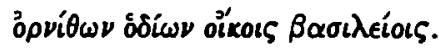




\section{Translation:}

A1: "When the wise seer saw the two Atreidae, different in character, he recognized in them the warlike devourers of the hare and the leaders of the expedition. Thus he spoke in riddles:

B: "In the course of time this expedition will destroy the city of Priam, all its cattle before the ramparts, the riches of the people, fate shall annihilate with force;

C1: if only some wrath from the gods does not overcloud the bit which has already been put on Troy by the army;

D1: For out of pity pure Artemis bears a grudge against the winged hounds of her father slaughtering the poor trembling hare with her young before birth - she loathes the meal of the eagles.

D2: The Fair One, so kind to the slow dewdrops of ravening lions, pleasant to the suckling raindrops of all animals that roam the field,

C2: consents to the fulfilment of these signs: favourable, but wrought with evil.

E: Iee, I call on the Healer that she does not cause for the Danaids some timeconsuming, ship-delaying adverse winds that prevent sailing, urging on another sacrifice, unlawful, not to be eaten, a creator of strife, part of the family, not fearing the man; for there stays a fearful, re-arizing, guileful householder, Menis who remembers and punishes on behalf of children."

A2: Such prophecies, together with many good things, Calchas announced to the royal house from the birds on the way."

The beginning (A1) and end (A2) of the pericope forms an outer ring, introducing and concluding with Calchas and how he spoke. In both groups both the birds and the Atreidae are also mentioned. Of larger importance here is that he is aware of the $\lambda \dot{\eta} \mu \alpha \tau \alpha$ ("personalities", "characters") of the Atreidae in A1, while in A2 the term oikols $B \alpha \sigma i \lambda \epsilon i o \iota \zeta$ refers to the palace of the Atreidae. The latter is part of a series of imagery in which the house is connected to either predetermined crime or alternatively to crime resulting from character (cf. Saayman: Dogs and Lions in the Oresteia, in a previous issue of Akroterion). Although imagery does not usually form stylistic patterns, it seems that here it is part of a ringcompositional arrangement.

The speech itself is contained inside this ring and starts with the interpretation of the omen, namely that the Greeks will take Troy (B).

But immediately after B, Calchas turns negative and is afraid that something will go wrong. He is afraid that some divine power will act with wrath and prevent the positive promises in the omen from taking place. C1 links both to Artemis (D1-C2) and to the

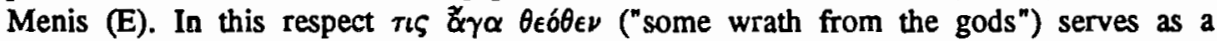
heading for the whole of the rest of Calchas' speech. The fear is twice motivated and identified with a known divine force and in both instances the motivation is marked by

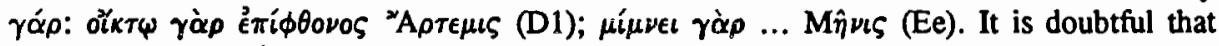
the repetition of $\gamma \alpha \dot{\alpha} \rho$ is unintended. If intended, as it seems to be, it surely links Menis and Artemis in a ringcompositional way to each other as two different manifestations of the

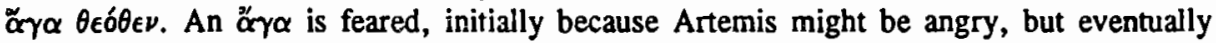
also because a Mînis may be at work. The rest of the analysis will show that the justification for the fear expressed in $\mathrm{Cl}$ starts out with Artemis and her reasons for 
demanding a counter sacrifice, but that the imagery prepares the way for, and builds up to, the Menis at the end of the justification section. Groups $\mathrm{Cl}$ to $\mathrm{C} 2$ form a type of ringcomposition on their own:

C1: Negative - Fear that some divinity will stop the war.

D1: Negative - Because Artemis is angry.

D2: Positive - Artemis' pleasant side.

C2: Positive - Artemis consents to the war.

In terms of semantic similarity and opposition groups D1 and D2 form a closer match than any one of them does with $\mathrm{C} 1$ or $\mathrm{C} 2$, because both $\mathrm{D} 1$ and $\mathrm{D} 2$ portray the attitude of Artemis towards animals. In D1 she is angry at the eagles for killing the hare, a killing

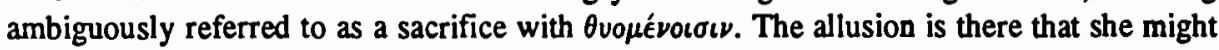
exact another sacrifice in retribution for the hare. But in D2 the opposite side of her feelings is portrayed, in positive terms, namely that she is kind and pleasant to the young of animals. This positive note continues into $\mathrm{C} 2$ where she consents and gives the go-ahead for the favourable outcome of the war, as portended in the omen. What she consents to, is firstly favourable $(\delta \in \xi<\alpha)$, and only secondly regrettable $(\kappa \alpha \tau \alpha \dot{\alpha} \mu \rho \phi \alpha \alpha)$. The positive outcome in $\mathrm{C} 2$ is detached from the contents of D2 in the sense that, why should a positive attitude towards young animals bring Artemis to consent to the war? This inconsistency on the narrative level is probably the reason for most of the debates on Artemis' anger. I would like to suggest that as the narrative is subordinate to the allusions in the imagery, so it is also subordinate to the feeling created by the contrast in Artemis' attitude. Initially she is hostile, and therefore suggested as the one who might bring about an $\alpha \gamma \alpha \theta \in \in \theta \in \nu$. The change to a positive attitude could suggest a subtle retraction of the initial connection between the wrath and Artemis. "She is hostile, therefore she is going to display wrath, but no, she is not hostile (and therefore will not display wrath)". Such a retraction would make perfect sense, because, since the next group (E) is devoted to Menis, Menis then replaces Artemis as the one who will display ${ }_{\alpha}^{\alpha} \gamma \alpha$.

Does Artemis extricate herself, or does the text perform the retraction?

In addition to the change from a negative to a positive attitude, to substitute Artemis with Menis, the internal structuring of both group D1 and D2 serves to draw the attention to a syllogism created by the two groups. Both groups D1 and D2 are basically ringcompositions, with parallelistic deviations. (Fraenkel 1962:85, referring to Ferrari, La Parodos, notes the second pattern.) In D1 Artemis' attitude is repeated parallelistically, while the objects of her attitude are arranged ringcompositionally in respect of one another. This is nicely varied in D2, where her attitude forms a surrounding ringcomposition, and a parallelism occurs in the objects of her attitude. The objects basically also form a ringcomposition, but in the second half of the ringcomposition the nouns and adjectives are separated to form a parallelism, merely by shifting $\theta \eta \rho \hat{\omega} \nu$ away from $\alpha \alpha^{\prime} \rho^{\prime} \nu 0 \mu \omega \nu$ to after $\phi \iota \lambda o \mu \alpha \alpha \sigma \tau o \iota s$. It is a basic tenet of discourse analysis that such deliberate structuring

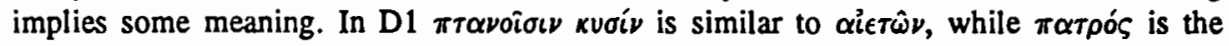
opposite of -Toxov in the next ring. The latter is already a very loose suggestion of contrast between parent and child, which is an important aspect of the Oresteia. In D2 both the basic ringcomposition as well as the parallelism create a stylistic contrast between children and parents. Obviously there is something important about the juxtaposition of parents and children. A quick interpretation in terms of the Oresteia could be that it merely highlights the parent-child conflict in general. But we must also take into account the ring in D1 which refers to eating, which ties this conflict to the Thyestes meal. By doing so, the syllogism between D1 and D2 can be recognised. 
On the level of the logical coherence of the meaning, groups D1 and D2 contain a syllogism, made up by the objects of Artemis' attitude. In D1 there are strong animals (eagles) killing weak ones. In D2 the weak animals are the children of the strong ones. The inference to be made is that the strong animals kill their own children. Applied to the Atreidae this refers backwards in time to the Thyestes meal and forward to the sacrifice of Iphigeneia.

As in the case of the imagery and the retraction (above), we must ask ourselves if Artemis is aware of the syllogism; because if she is not, then the syllogism is better linked to Menis than to Artemis. Both the syllogism, as well as the distinction between adults and children

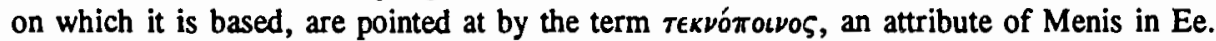

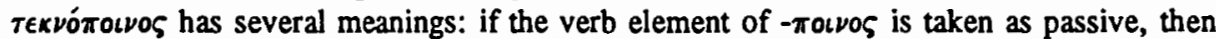
it means either "avenging a child/children" or "punishing a child". If the verb stem is active it means "a child punishing/avenging". In other words it may refer to all the crimes of the Pelopidae: the Thyestes meal, the sacrifice of Iphigeneia, the death of Agamemnon for that, as well as to Orestes killing his mother. Thus the syllogism and the stylistic contrasting of parents and children seem to connect the criminal conflict between adults and children to Menis, which is in line with the other instances of Menis in the Oresteia, where she is always involved in crime and retribution. Whereas the involvement of Artemis is textually motivated well enough by the direct meaning of the text (on the narrative level), namely that she abhors the killing of the hares because she loves little animals, the allusion to parents killing children and being punished for it, should rather be seen as supplying motivation only for the Menis which follows later in the text.

After the symmetric change from the negative in C1 and D1 to the positive in D2 and C2 and the resulting suggested retraction of Artemis' anger, group $E$ is again surprisingly negative. Although group $\mathrm{E}$ starts out with real as well as apparent references to Artemis, the main force in group $E$ is, ultimately, Menis. Because of the retraction Artemis is only referred to indirectly in $\Pi \alpha \iota \hat{\alpha} \nu \alpha$, and epithet of her brother Apollo. The fears for adverse winds in Eb suggest Artemis, but the following text increasingly implies that Menis is meant, culminating in the naming of Menis right at the end of group E. Group $E$ repeats the topics of the previous groups, but only their ominous side, which resides especially in the syllogism and the imagery: The $\gamma \rho \hat{i} \phi o \zeta$ "overshadow the bit already put on Troy"

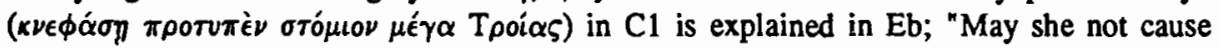
delaying winds to hold the fleet back ...". Artemis is assumed here.

Ec and Ed apparently portray Artemis as "eagerly desiring another sacrifice, one that is unlawful and may not be eaten", clearly indicating a human sacrifice. But the word $\sigma \pi \epsilon v_{0} \mu^{\prime} \in \operatorname{vo}$ is too strong in describing Artemis' demand for another sacrifice. The medium form of the verb here is unusual (Fraenkel 1962:91), therefore probably ambiguous. Artemis "desires" another sacrifice, but why would she do it "eagerly", instead of merely "demanding" or "insisting on" it? It makes better sense that the Menis would be "eager" for "another sacrifice, ... an inborn creator of strife", instead of Artemis, and then not necessarily in the sense of "desiring", but of "promoting" (translation equivalents from Liddell and Scott). Despite the syntax, $\sigma \pi \epsilon v \delta o \mu \epsilon \nu \alpha$ seems to contain word-play referring to Menis. The sacrifice as "an inborn creator of strife" also alludes to Menis, who is a vengeful deity. It links up with the notion of parent-child conflict of the syllogism, as well as with the allusions in the imagery. The sacrifice will cause more strife, that is, murders. The murder of Agamemnon is alluded to with "not fearing the husband". In each instance the divine force behind the events would rather be Menis than Artemis.

In Ee the alternative manifestation of the $\alpha^{\nu} \gamma \alpha \theta \epsilon \theta^{\prime} \theta \epsilon \nu$ is identified as a re-arising Menis in the house, who remembers things (crimes) and is rexvómolvos. As far as the direct stating 
of the identity of the divinity causing the sacrifice is concerned, Menis at this point usurps the part played by Artemis in the trilogy.

The transition from Artemis, who might demand a sacrifice because of the hare killed in the omen, to a Menis linked to past and future crimes in the family of the Pelopidae, is

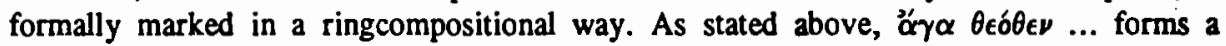
heading for D1 to E. At the start of this section, Artemis is introduced by name with $\gamma \dot{\alpha} \rho$ .$^{2}{ }^{2}$ A The identification of the ${ }_{\alpha}^{\prime \prime} \gamma \alpha \theta \epsilon \dot{\theta} \theta \epsilon \nu$ therefore forms a formal ringcompositional ring. This ring marks the transition from the role of Artemis to the role of Menis. The scope of issues involved has widened to such an extent that Menis supercedes Artemis as cause of the sacrifice; or perhaps one should rather say, as cause of the series of crimes relevant to the intrigue of the Oresteia.

The two forces operate on two different levels. Artemis operates on the level of the surface structure of the text (the narrative level), and therefore demands a sacrifice for what the text says on this level, namely that she wants retribution for the killing of the real hare. After the sacrifice scene Artemis is never mentioned again and she plays no further part in the trilogy. Menis, on the other hand, operates on the same level as the imagery. She is a motivational force behind every crime suggested by the imagery and, just as the imagery pervades the whole trilogy, so do Menis and the associated Erinyes as part of the ethical controversy that forms the intrigue.

The presence of Artemis in the text is motivated clearly enough by the description of her love for young animals. The Menis is motivated by the allusions in the imagery and the other literary devices. Lawrence (1976:102) said that "it should be reiterated that the text does not clearly indicate the extension of Artemis' anger beyond the content of the portent". It now seems that, though not clearly, the text does indicate by its artistry the limited role of Artemis.

\section{BIBLIOGRAPHY}

Denniston, J.D. and Page, D. 1957. Aeschylus Agamemnon. Oxford: Clarendon Press.

Fraenkel, E. 1962. Aeschylus Agamemnon II. Oxford: Clarendon Press.

Lawrence, S.E. 1976. "Artemis in the Agamemnon." AJPh 97, 97-110.

Lebeck, A. 1971. The Oresteia: A Study in Language and structure. Cambridge: Harvard University Press.

Peradotto, J.J. 1969. "The omen of the Eagles and the $\hat{\eta}$ or of Agamemnon." Phoenix 23, 237-263.

Whallon, W. 1961. "Why is Artemis angry?" AJPh 82, 78-88.

Acknowledgement: The TLG electronic texts were used for word searches. 